\title{
Fractionated Stereotactic Radiation Therapy
}

National Cancer Institute

\section{Source}

National Cancer Institute. Fractionated Stereotactic Radiation Therapy. NCI Thesaurus.

Code C156862.

Stereotactic radiation therapy that uses multiple, smaller doses of radiation therapy spread over several treatment session. 